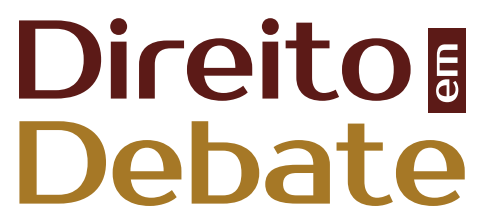

Revista do Departamento de Ciências Jurídicas e Sociais da Unijuí

Editora Unijuí - Ano XXX - n. 56 - jul./dez. 2021 - ISSN 2176-6622

\title{
DESENVOLVIMENTO X RESERVA DO POSSÍVEL NO CENÁRIO DO ESTADO DEMOCRÁTICO BRASILEIRO: O Caso dos Refugiados Venezuelanos
}

\author{
http://dx.doi.org/10.21527/2176-6622.2021.56.10309
}

Recebido em: 4/3/2020

Modificações solicitadas em: 18/11/2020

Aceito em: 4/1/2021

Antônio José de Mattos Neto

Universidade Federal do Pará (UFPA). Belém/PA, Brasil.

Thaise Roberta Colares Leal

Autora correspondente. Universidade da Amazônia - Unama. http://lattes.cnpq.br/4106443918187943. https://orcid.org/0000-0002-6385-7381. thaisercleal@gmail.com

\section{RESUMO}

O presente artigo objetiva apresentar reflexões sobre a realização dos direitos fundamentais sociais que compõem o mínimo existencial para estrangeiros em situação de refúgio, considerando, além do arcabouço jurídico brasileiro, a posição inicial do Supremo Tribunal Federal (STF) na Ação Civil Originária que tem por objeto a entrada de venezuelanos no Brasil, processo este ainda em curso. 0 método empregado foi o dedutivo, a partir de pesquisas bibliográfica e jurisprudencial. Conclui-se que os direitos fundamentais sociais garantidos aos refugiados na Lei no 9.474, de 22/7/1997, devem ser realizados concretamente, não comportando o argumento da reserva do possível para seu incumprimento, no ambiente do Estado Democrático de Direito.

Palavras-chave: Direitos fundamentais sociais; refugiados; mínimo existencial; reserva do possível; Estado Democrático de Direito.

\section{DEVELOPMENT VS. POSSIBLE RESERVE IN THE SCENARIO OF THE BRAZILIAN DEMOCRATIC STATE:} THE CASE OF VENEZUELAN REFUGEES

\section{ABSTRACT}

This article aims to present reflections on the realization of the fundamental social rights that make up the minimum existential for foreigners in a situation of refuge, considering, in addition to the Brazilian legal framework, the initial position of the Supreme Federal Court (STF) in the Original Civil Action that is aimed at the entry of Venezuelans in Brazil, a process that is still ongoing. The deductive method was used, based on bibliographic and jurisprudential research. It is concluded that the fundamental social rights guaranteed to refugees in Law 9.474 , on $07 / 22 / 1997$, must be realized concretely, not involving the argument of reserving the possible for their non-compliance, in the environment of the Democratic State of Law.

Keywords: Fundamental social rights; refugees; minimum existential; reserving the possible; Democratic State of Law. 


\section{INTRODUÇÃO}

No quadro que precede a promulgação da Constituição da República Federativa do Brasil, em 1988, observa-se, na contramão da realização dos direitos fundamentais, o período da ditadura militar (1964-1985), quando houve muitas privações humanas e perseguições políticas. Falar disso é importante para que se tenha a dimensão da importância da Constituição Republicana, pois assim como, após a Segunda Guerra Mundial (1938-1945), a Declaração Universal dos Direitos Humanos (1948) significou um marco histórico para a proteção dos direitos da humanidade, a Constituição Federal de 1988 significou a restauração e reconhecimento de direitos básicos da condição humana, no Brasil. Com efeito, nos cenários internacional e nacional aspiraram-se à realização dos direitos humanos e da democracia.

O Brasil é prestigiado em suas relações internacionais graças ao engajamento em matérias humanitárias. Desde o fim da Primeira Guerra Mundial (1914-1918), participando da Liga das Nações e depois sendo um dos primeiros países-membros da Organização das Nações Unidas (ONU), o país empenhou-se em ser não apenas signatário de tratados internacionais sobre a proteção dos direitos humanos, como também incorporá-los na Constituição da República e em leis infraconstitucionais.

No que respeita aos refugiados, a Convenção Relativa ao Estatuto dos Refugiados de 1951 da ONU, inovando devido à inexistência de normatização anterior sobre a matéria, estabeleceu a definição de refugiado e quais são os seus direitos e deveres, ressaltando a importância do envolvimento de todos os seus Estados-membros para a proteção dessas pessoas em estado de vulnerabilidade extrema.

Essa Convenção foi absorvida pelo Brasil na Lei no 9.474 de 22 de julho de 1997, que estabelece a criação do Comitê Nacional para os Refugiados (Conare), seu funcionamento, o rito de reconhecimento jurídico do refugiado e os deveres e direitos desses sujeitos em território brasileiro, cujos direitos não devem ser apenas garantidos, mas também promovidos pelo Estado brasileiro.

O presente artigo tem por objetivo circunscrever o mínimo existencial do refugiado no Direito brasileiro, a partir do recorte analítico do caso dos venezuelanos, que passaram a entrar no Brasil pela fronteira terrestre, no Estado de Roraima, e que resultou em judicialização perante o Supremo Tribunal Federal (STF) e que ainda se encontra em trâmite processual. Devido ao fato de não estar decidida a matéria, o presente trabalho, na utilização do julgado, focará apenas na parte da decisão do Excelso Pretório de não fechar as fronteiras com a Venezuela.

Trata-se de Ação Cível Originária 3121 RR, ajuizada pelo Estado de Roraima contra a União, tendo como relatora a ministra Rosa Weber, e por objeto vários pedidos, podendo ser, geral e sinteticamente, interpretados como auxílios financeiro e médico da União para o Estado Federado, tendo em vista o ingresso dos venezuelanos no território roraimense, o fechamento da fronteira para evitar novos ingressos e outros pedidos de menor impacto para o presente estudo.

Nesse sentido, a ré manifestou-se no sentido de informar que já realizava ações por meio do Ministério da Defesa, fornecendo apoio logístico e humanitário, em ação denominada "Operação Acolhida", por meio da qual foram realizados traslados dos imigrantes para outros Estados do Brasil.

A ministra relatora concedeu medida liminar para que tanto Estado de Roraima quanto União prestem ajuda humanitária aos refugiados, o que ensejou acordo parcial entre as partes. Demais pontos que não exigiam urgência para o suporte de atendimento humanitário foram deixados fora do acordo, restando como objeto a ser decido pelo STF em julgamento futuro, estando, portanto, ainda em curso o processo judicial.

A partir do uso do método dedutivo e com pesquisas bibliográfica e jurisprudencial, o presente texto está dividido em quatro partes principais, além desta introdução. A primeira apresenta autores que contribuem de forma empírica sobre a importância do desenvolvimento como liberdade, da interpretação das regras, da importância dos princípios nas decisões judiciais, o mínimo existencial e sobre a reserva do possível, bem como a universalidade dos direitos, formando assim a fundamentação necessárias às análises que serão feitas conforme o proposto.

Posteriormente, são referidos os direitos fundamentais sociais na Constituição Federal e seus reflexos na Lei de Refugiados no Brasil. Este cenário jurídico deu ensejo à decisão do Supremo Tribunal Federal sobre o 
caso dos refugiados venezuelanos no país, judicializado pelo Estado-membro de Roraima, cujo teor decisório, ao lado do ordenamento jurídico legal, é sucintamente tratado na pesquisa.

A terceira seção debruça-se sobre breve e genérica exposição da Lei dos Refugiados brasileira, situando-a no contexto internacional contemporâneo, em realce à necessidade de conceder concretamente ao refugiado o mínimo existencial que é garantido em lei.

O último tópico congrega como objetivo principal reflexões sobre os direitos fundamentais sociais aos refugiados que buscam no território brasileiro um abrigo, a partir do cenário jurídico nacional formado tanto pelo ordenamento legal brasileiro com rasgos de sua interpretação doutrinária como pela decisão do Supremo Tribunal Federal na Ação Cível Originária 3121 RR, já referida.

\section{O DESENVOLVIMENTO AMARTYANO E SUA RELAÇÃO DIRETA COM OS DIREITOS FUNDAMENTAIS}

Amartya Sen (2000) estabelece percepções sobre a correlação existente entre desenvolvimento e liberdade. A liberdade é o núcleo do desenvolvimento, de modo que quando a sociedade tem acesso à saúde, à educação, aos serviços sociais e outros direitos, é possível que estes também sejam parte do processo de desenvolvimento local. Sen (2000, p. 18) conceitua a liberdade em sentido avaliatório (em que há uma constante verificação sobre o aumento da liberdade alcançada) e no sentido de eficácia (quando a liberdade é parte condicionante do desenvolvimento).

O bem-estar social, para Amartya Sen (2000), refere às oportunidades sociais, políticas ou econômicas, a cujo acesso resulta em qualidade de vida individual e coletiva, ao passo que o desenvolvimento social está relacionado às liberdades individuais. Nesse sentido, pessoas que são livres politicamente e que exercem a liberdade de expressão estão mais próximas de construir uma sociedade mais socialmente igualitária e desenvolvida.

Países em que a desigualdade social é rotina mostram que apenas alguns grupos sociais têm acesso às liberdades políticas, econômicas e sociais. Na perspectiva de Sen (2000), essas disparidades entre homens e mulheres, negros e brancos, e acrescente-se, nacionais e refugiados, são consequências de oportunidades díspares que são verdadeiras barreiras para a igualdade social e para que se alcance uma sociedade com justa distribuição de renda. Neste sentido, Sen (2000) acredita que o preconceito social, político e/ou econômico gera a privação de liberdades destes indivíduos e/ou grupos.

Um último ponto que se faz necessário para as reflexões propostas para este artigo é a discussão suscitada por Sen (2000) sobre pobreza coletiva. Oportunidades sociais adequadas possibilitam que os indivíduos possam decidir livremente sobre o destino que querem para si próprios, fazendo com que isto seja um ciclo de facilitação de oportunidades para pessoas que enfrentam privações. A pobreza coletiva tem a ver com governos autoritários. Se não há um ciclo de oportunidades, há um ciclo de privações.

A privação política, que não permite às pessoas escolherem seus governantes, as faltas de liberdade de expressão e de associação política para promover discussões públicas sobre planejamento nacional geram privações econômicas. O resultado de uma nação que é dirigida por ditadores é a falta de empatia destes em relação às necessidades da população. De fato, países democráticos, por terem de lidar constantemente com o processo de eleição e com a opinião pública, dificilmente enfrentam situações de fome e pobreza coletiva. Onde há liberdade, há desenvolvimento. A riqueza é a possibilidade de fazer coisas para si, para a comunidade e em prol de causas; por outro lado, a insegurança econômica promove a ausência de direitos e de liberdades democráticas (SEN, 2000, p. 48).

\subsection{Do mínimo existencial e da reserva do possível}

Ana Olsen (2008a, p. 63), ao escrever sobre "Direitos Fundamentais Sociais como Regras e Princípios", objetiva identificar se as normas do direito fundamental social, no texto fundamental, aproximam-se mais do modelo de princípio ou de regra - a partir do modelo preconizado por Robert Alexy (apud OLSEN, 2008a, p. 63) - como forma de pensar suas consequências jurídicas sobre a reserva do possível. Para a autora, a diferença entre regras e princípios "é uma decorrência da atividade do intérprete, de modo que regras e princípios não seriam duas subespécies de normas, mas sim dois tipos de estratégias de interpretação" (OLSEN, 2008a, p. 67). 
O princípio é um mandamento jurídico que poderá ser diversificado a partir das circunstâncias fáticas ou jurídicas, de modo a gerar, ao final, um mandamento definitivo ótimo. Já no caso da regra, cabe ao intérprete apenas cumprir a conduta prevista em grau definitivo da norma, adotando uma postura coerente com o mandado, proibição ou permissão nela estampados (OLSEN, 2008a, p. 67-68).

Olsen (2008a) conclui que é um desafio identificar quais são as normas de direitos fundamentais previstas na Constituição que correspondem ao mínimo existencial. E esclarece que este é um termo político que limita a realização do direito social baseado no argumento da escassez econômica do país. Isto é, a determinação jurisdicional de um direito social é condicionada à economia, constituindo a única exceção de direito a vida humana. De fato, a pesquisa da autora aponta que "o não reconhecimento dos direitos sociais como verdadeiros direitos subjetivos é mais uma questão político-ideológica que jurídica" (OLSEN, 2008a, p. 112).

Ricardo Torres (2003) analisa o problema da transição dos direitos sociais prestacionais em mínimo existencial. $\mathrm{Na}$ estrutura dos direitos fundamentais movem-se valores éticos e jurídicos, princípios fundamentais e estruturais e princípios de legitimação. $O$ indivíduo não pode ser privado do mínimo para viver, segundo o princípio da liberdade fática; neste patamar, o autor cita o direito à alimentação, à segurança, à saúde e à educação.

Sob argumento algum, nem mesmo o da escassez econômica, o indivíduo poderia ser privado desse mínimo existencial. "Sem o mínimo necessário à existência cessa a possibilidade de sobrevivência do homem e desaparecem as condições iniciais de liberdade" (TORRES, 2003, p. 5).

Baseando-se nos princípios da igualdade, da justiça e da solidariedade, o autor evidencia que o primeiro princípio nivela as pessoas sobre o direito a ter acesso a direitos. O princípio da justiça relaciona-se à segurança como valor ético e moral que garante em todas as instâncias de que o direito será garantido, ao passo que o da solidariedade é "sobretudo uma obrigação moral ou um dever jurídico" (TORRES, 2003, p. 10). Apoiado em Jürgen Habermas, o autor entende que o princípio da solidariedade é um elemento indispensável na construção do Estado de Segurança (apud TORRES, 2003, p. 10).

Da dignidade da pessoa humana emanam todos os direitos fundamentais, conforme os princípios da Constituição contidos em seu artigo 1‥ E para o bom andamento da efetivação e promoção desses direitos, é fundamental que a sociedade viva a democracia como meio de garantir que as pessoas tenham não apenas acesso ao direito, como também tenham a possibilidade de serem participantes deste processo (TORRES, 2003, p. 11-20).

Assim como Torres (2003), Ana Olsen (2008b) afirma que o argumento da reserva do possível é uma barreira que impede a realização dos direitos fundamentais sociais. Dessa forma, a reserva do possível deve ser entendida a partir da ideia de que "a escassez de recursos seria elemento a inviabilizar o próprio reconhecimento do direito subjetivo a prestações sociais" (OLSEN, 2006, p. 194). De acordo com esta perspectiva restritiva, a realização do direito social, por demandar um custo, deveria ser submetida à realidade orçamentária do Estado.

A reserva do possível é um argumento jurídico factual utilizado frequentemente quando se lida com a garantia dos direitos fundamentais sociais. Segundo Olsen (2006), trata-se aspectos lógicos da escassez de recursos. Isto é, a práxis do Direito deve impreterivelmente estar em conformidade com a realidade, regulando as demandas jurídicas de acordo com as possibilidades reais.

Observando o caso dos direitos fundamentais sociais, Olsen (2008b) afirma que a escassez é um argumento frequente. Neste sentido, há uma (maior) pressão política que se sobrepõe ao direito. Urge levar em consideração o fato de que em diferentes proporções, os direitos sociais acabam se relacionando com a dignidade humana. Se o argumento da escassez de recursos orçamentários é utilizado com frequência, "a preocupação com a redução da desigualdade social, o combate à pobreza e a realização da dignidade humana assumem especial relevância" (OLSEN, 2008b, p. 298).

\subsection{Da perspectiva de universalidade dos direitos fundamentais sociais}

Da gama de direitos fundamentais estão os direitos sociais, que segundo Matos (2015), possuem um regime jurídico complexo e próprio, e, por isso, demanda outro entendimento sobre sua universalidade. Esta afirmação parte do pressuposto de que os direitos fundamentais sociais atendem às necessidades específicas do ser humano e que podem sofrer alterações de acordo com as peculiaridades de cada sociedade/lugar. 
A complexidade da universalidade dos direitos sociais reside justamente nessas peculiaridades. Universalidade é aquilo que diz respeito a todos, sem distinção de nacionalidade, credo, gênero, classe social ou qualquer outro fator. Sendo assim, enquanto se pode falar tranquilamente sobre a universalidade dos direitos humanos (o direito à vida e à liberdade de expressão, por exemplo), pode-se suscitar discussões sobre a universalidade dos direitos sociais (educação e saúde, por exemplo), pois as práticas destes direitos podem ser culturalmente diversas (MATOS, 2015, p. 29).

Em relação à universalidade de direitos sociais, aplicados aos refugiados - conforme recorte proposto por este artigo - Andrew Linklater (1998) acredita que a responsabilidade do Estado diz respeito não apenas aos seus nacionais, pois considera que, para além da organização estatal, está o princípio da universalidade. Ou seja, quando um direito humano é violado em qualquer parte do mundo a sociedade internacional deve intervir.

Para Linklater (1998), apesar de cada tempo desfrutar de um ciclo, eles não estão separados, e uma vez que ideologias universalistas foram possíveis em outros séculos, ainda há perspectivas para que se desenvolvam. Sobre a questão dos refugiados, a abordagem cosmopolita acrescenta:

Poucos argumentariam que o direito à livre circulação deve permanecer primordial quando a evidência é que uma sociedade não pode absorver refugiados adicionais sem causar uma séria interrupção do seu modo de vida ou esticar seus recursos materiais para o ponto de ruptura. (...) Um objetivo de abordagens cosmopolitas é defender os direitos dos refugiados em um mundo de Estados soberanos em que nenhum direito de refúgio automático é conferido aos povos apátridas (LINKLATER, 1998, p. 54).

O sentimento universalista pontuado por Linklater (1998) aplica-se na prática sobre a assistência aos refugiados, como sendo estranhos com problemáticas externas, mas que deveriam despertar um dever e consciência moral para conceder-lhes o direito de residência e sobrevivência. O cosmopolitismo engloba a sociedade, fazendo com que o poder de decidir sobre a obrigatoriedade do direito não seja de um órgão Legislativo superior.

A busca por refúgio, antes de mais nada, é querer estar em segurança, seja no âmbito de proteção ou de garantia de direitos. Neste cenário, é inerente ao Estado a responsabilidade de proteger, possibilitando a harmonização da paz social. Ressalta-se que "observar os ditames da justiça social, pacificar conflitos e conscientizar que os povos precisam obter do Estado o mínimo existencial e a satisfação de suas necessidades básicas" é uma função do Estado (ANDRADE; RAMINA, 2018, p. 37).

Ainda segundo Andrade e Ramina (2018), quando se analisa o direito dos refugiados faz-se necessário observar os princípios da dignidade humana, haja vista que tal princípio funciona como norteador para todo o ordenamento jurídico, pois sem observar os direitos originários do ser humano - sem distinções - as privações e injustiças tornam-se estruturais.

\section{NOTAS SOBRE A LEI DOS REFUGIADOS}

A presente seção visa a apresentar sucinta referência dos direitos sociais no Texto Constitucional, o que desdobrou em espelhar na construção da Lei dos Refugiados no país cujo cenário jurídico propiciou ao Supremo Tribunal Federal emitir sua compreensão sobre a questão dos refugiados venezuelanos no Brasil.

\subsection{A realização dos Direitos Sociais e o Índice de Desenvolvimento Humano do Brasil}

Após o regime da ditatura militar no Brasil (1964-1985), a aspiração aos ares democráticos impulsionou o país a promulgar a democrática Constituição Federal de 5 de outubro de 1988, que concebeu como paradigmas a democracia e os direitos humanos revelados no exercício dos direitos sociais e individuais, na liberdade, na segurança, no bem-estar, no desenvolvimento, na igualdade e na justiça como valores supremos de uma sociedade fraterna, pluralista e sem preconceitos, fundada na harmonia social e comprometida, na ordem interna e internacional, com a solução pacífica das controvérsias (valores insculpidos no Preâmbulo da Constituição Federal).

Socioeconomicamente, pode-se medir o acesso das pessoas aos direitos fundamentais sociais por meio do Índice de Desenvolvimento Humano (IDH). Segundo o United Nations Development Programme (2019), no ranking mundial de desenvolvimento humano, o Brasil ocupa a 79a posição, atrás de países como México, Cos- 
ta Rica e Albânia. O ranking mundial de Desenvolvimento Humano considera quatro principais indicadores: a expectativa de vida, expectativa de anos de escolaridade, anos médios de escolaridade e a renda nacional per capita. Segundo o Relatório do Programa de Desenvolvimento das Nações Unidas, entende-se a medida de desenvolvimento: muito alto $(0,800$ ou acima), alto $(0,700-0,799)$, médio $(0,550-0,699)$ e baixo (abaixo de $0,550)$.

Segundo o United Nations Development Programme (2017), em 2014 o ranking global do Brasil era de 0,752, em 2017, de 0,759, e em 2018 era de 0,761. Os dados a seguir apresentados referem-se ao ano de 2017: expectativa de vida $(75,4)$, expectativa de anos de estudos $(15,4)$, renda nacional bruta $(13,755)$, desigualdade social $(0,578)$, desigualdade em educação $(22$,$) , qualidade da educação (51)$, qualidade de saúde (36), pobreza multidimensional $(79,4)$, intensidade de privações $(58,6)$ e pessoas vivendo abaixo da linha da pobreza $(8,7)$. Um valor de zero representa igualdade absoluta, um valor de cem desigualdade absoluta.

O relatório do Programa das Nações Unidas para o Desenvolvimento (Pnud) de 2017 define o Brasil como um dos países mais desiguais do mundo, destacando-se que em 2016 ocupava o $10^{\circ}$ lugar no ranking mundial. Tal desigualdade representa sérios desafios para o Estado e suas políticas públicas. Por recomendação das Nações Unidas, é necessário que haja o reconhecimento de tais desafios a fim de superá-los, mostrando-se importante neste processo considerar em equidade todos os grupos humanos presentes no país (PNUD, 2017, p. 8).

\subsection{Lei no 9.474, de 22 de julho de 1997}

Cabe, em primeiro lugar, delimitar o conceito de refugiado para que não haja confusão com o termo imigrante. Segundo o Alto Comissariado das Nações Unidas para Refugiados (Acnur), refugiado é o indivíduo forçado a sair do seu país por ter sido vítima de perseguição de religião, raça, gênero, nacionalidade, grupo social ou opinião política; enquanto que imigrante é aquele que possui a escolha de sair de seu país ou não (ACNUR, 2018).

Em 1951 o Acnur, em conjunto com os países-membros da ONU, estabeleceu o Estatuto dos Refugiados, com o objetivo de rever e codificar os acordos anteriormente realizados, principalmente após a Segunda Guerra Mundial (1938-1945), quando havia milhares de pessoas deslocadas.

Segundo Peixoto (2020), os refugiados reconhecidos por um determinado país possuem direitos e deveres, organizando o período de acolhimento pautado na segurança jurídica. E o primeiro órgão regulador do refúgio é o Acnur, que junto aos seus países-membros formula as leis de refúgio, auxilia governos em todo o processo e emite relatório à sociedade civil internacional sobre a situação dos refugiados no mundo.

No caso do Brasil, 46 anos após se tornar signatário do Estatuto de Refugiados, promulgou a Lei no 9.474, de 22 de julho de 1997, que define mecanismos para a concretização do Estatuto dos Refugiados de 1951. Para o recorte do presente trabalho, importa o artigo 11, que cria o Comitê Nacional para os Refugiados (Conare), responsável pela logística de acolhimento de refugiados no Brasil, e que se tornou referência internacional.

Os procedimentos práticos da Lei no 9.474 são manifestados por meio do Conare, que tem as seguintes competências, em consonância com a Convenção sobre o Estatuto dos Refugiados de 1951, com o Protocolo sobre o Estatuto dos Refugiados de 1967 e com as demais fontes de Direito Internacional dos refugiados, conforme determina o artigo 12:

\footnotetext{
I - analisar o pedido e declarar o reconhecimento, em primeira instância, da condição de refugiado;

II - decidir a cessação, em primeira instância, ex officio ou mediante requerimento das autoridades competentes, da condição de refugiado;

III - determinar a perda, em primeira instância, da condição de refugiado;

IV - orientar e coordenar as ações necessárias à eficácia da proteção, assistência e apoio jurídico aos refugiados;

V - aprovar instruções normativas esclarecedoras à execução desta Lei (BRASIL, 1997).
} 
O Conare é composto por um Conselho que delibera sobre o acolhimento dos refugiados que, de acordo com artigo 12, inciso IV, da Lei no 9.474/97, deve orientar e coordenar o processo de acolhimento dos refugiados no país. Essas ações são realizadas por intermédio deste Conselho Deliberativo formado por representantes dos Ministérios da Justiça, do Trabalho, da Saúde e da Educação, além de um representante da sociedade civil e da Acnur.

A formação desse Conselho permite a realização de um plano conjunto que atende aos refugiados e em conformidade aos direitos sociais constitucionais. Peixoto (2020) esclarece que o Conare reúne diversos ministérios e possui o poder decisório sobre o acolhimento ou não dos refugiados. $E$, para além desta função, também é responsável pela elaboração e execução de políticas públicas de acolhimento.

Ademais, o artigo 48 da Lei no 9.474/97 determina que sua interpretação deve ser realizada "em harmonia com a Declaração Universal dos Direitos Humanos de 1948, com a Convenção sobre o Estatuto dos Refugiados de 1951, com o Protocolo sobre o Estatuto dos Refugiados de 1967 e com todo dispositivo pertinente de instrumento internacional de proteção de direitos humanos com o qual o governo brasileiro estiver comprometido".

Após regularização no Brasil, por meio do Conare, o refugiado pode desfrutar dos mesmos direitos de cidadãos estrangeiros em situação regular no país, estando sob a responsabilidade do Estado brasileiro. Apesar, no entanto, dos aparatos logístico e jurídico disponíveis para a questão dos refugiados, ainda encontram muitas dificuldades para terem oportunidades e acesso a estes direitos (ACNUR, 2018, p. 18-21).

Em 2014 o Brasil sediou o evento Cartagena+30, em comemoração aos 30 anos da reunião de diversos países na Colômbia que estabeleceram diálogo regional sobre refúgio, apátrida e deslocamento interno. $\mathrm{Na}$ ocasião, o Brasil comprometeu-se com os três pilares da reunião por meio da Declaração e do Plano de Ação do Brasil que traçavam os procedimentos práticos para proteção internacional desses grupos. Diversos Estados adotaram o Plano e tiveram com umas das principais preocupações a integração local (ACNUR, 2018, p. 27).

Como resultado do empenho do Estado brasileiro na causa dos refugiados, segundo publicação das Nações Unidas no Brasil (2014), entre 2010 e 2014 "o país assistiu o número de novas solicitações de refúgio aumentar em mais de $800 \%$ ". O país chegou a ser referência nas Américas sobre o acolhimento e empoderamento dos refugiados. Segundo o Acnur (2018, p. 18), "em 2017, o país registrou uma população de 10.141 refugiados reconhecidos, provenientes de mais de 80 países diferentes, havendo mais de 30 mil pedidos de refúgio a serem analisados pelo Conare".

Entre as dificuldades de acolhimento dos refugiados estão o acesso à educação e oportunidade de trabalho. Conforme explica o Acnur (2018), saúde e moradia também têm sido um dos desafios para os refugiados no país, apesar dos esforços realizados pelo Conare, daí a importância do envolvimento da iniciativa privada, do poder Judiciário e da sociedade civil neste processo. Ademais, formou-se um projeto denominado Rede Solidária para Migrantes e Refugiados que "reúne aproximadamente 67 entidades que atuam em todo o território brasileiro, muitas delas em pontos isolados de fronteira" (ACNUR, 2018, p. 21).

Vale ainda ressaltar que o Brasil é parte no âmbito internacional de proteção aos refugiados: Declaração de Cartagena sobre Refugiados (1984), Declaração de San José sobre Refugiados e Pessoas Deslocadas (1994), Plano de Ação do México para Fortalecer a Proteção Internacional dos Refugiados na América Latina (2004), Declaração de Brasília Sobre a Proteção de Refugiados e Apátridas no Continente Americano (2010) e a Declaração de Princípios do Mercosul sobre Proteção Internacional de Refugiados (2012) (ACNUR, 2014, p. 1).

Rocha e Guerra (2019, p. 22) entendem que, no que diz respeito aos direitos dos refugiados, apesar dos "dispositivos legais existentes no ordenamento jurídico brasileiro, bem como com os consagrados no sistema internacional (...) evidencia-se que ainda se mostram não tão eficazes quanto sua natureza propõe". De fato, é necessário que reflexões sobre a realização dos direitos dos refugiados sejam feitas, com o objetivo de tentar minimizar danos que ainda possam vir a sofrer. 


\section{REFLEXÕES SOBRE A REALIZAÇÃO DOS DIREITOS FUNDAMENTAIS SOCIAIS PARA REFUGIADOS NO BRASIL: O CASO DOS VENEZUELANOS}

Amartya Sen (2000), ao tratar de desenvolvimento local, pondera que o acesso à saúde, educação, serviços sociais e outros direitos são partes do processo que ao mesmo tempo conduz à liberdade e ao desenvolvimento.

A veracidade da lógica entendida por Sen (2000), que demonstra a intrínseca relação entre liberdade, desenvolvimento e os direitos sociais, pode ser constatada juridicamente na Constituição Federal Brasileira. Com efeito, o desenvolvimento esperado para o país está relacionado às garantias fundamentais, ou, mais especificamente, a qualidade de vida e a liberdade dos cidadãos dependem do seu acesso aos direitos sociais.

Nos termos da Constituição, artigo 6ㅇ, os direitos fundamentais sociais são "a educação, a saúde, a alimentação, o trabalho, a moradia, o transporte, o lazer, a segurança, a previdência social, a proteção à maternidade e à infância, a assistência aos desamparados".

Os dados anteriormente apresentados pelo Índice de Desenvolvimento Humano (IDH) do Brasil, em 2017, evidenciam dois termos utilizados por Sen (2000): a liberdade avaliatória e a liberdade com eficácia. Com relação à primeira, é possível medir o progresso do país a partir dos relatórios do Programa das Nações Unidas para o Desenvolvimento, por meio do acesso à saúde, educação e renda do brasileiro, demonstrando que entre 2014 e 2017 o seu progresso no ranking global foi de apenas 0.007.

Referente à liberdade com eficácia, Sen (2000) considera que a liberdade e o desenvolvimento caminham juntos se o indivíduo tem acesso à educação, saúde, segurança e outros direitos, resultando em desfrutar de mais liberdade e desenvolvimento. Na contramão do que é indicado por Sen (2000), o Brasil é um país com elevadas taxas de desigualdade social, de educação e de renda, com pessoas que vivem abaixo da linha da pobreza $(8,7 \%)$, outras em intensidade de privações $(58,6 \%)$ e em pobreza multidimensional, que são em vários setores da vida $(79,4 \%)$.

Quais, no entanto, são os motivos que ranqueiam o Brasil como um dos dez países mais desiguais do mundo? Como detentor de inúmeras riquezas naturais e que arrecada mais de um trilhão de reais de tributos em apenas seis meses, as razões atravessam a desigualdade estrutural - consequência da construção histórica do país e permanência da situação - a má administração pública e a corrupção. Indivíduos distantes das oportunidades políticas, sociais e econômicas não desfrutam do Estado de Bem-Estar Social, que é parte da qualidade de vida individual e coletiva.

Um país que tem $8,7 \%$ de sua população vivendo abaixo da linha da pobreza, com baixas oportunidades e pouca disponibilidade de realização de direitos fundamentais sociais de forma equitativa, pode acolher adequadamente estrangeiros em situação de refúgio e que serão, em um primeiro momento, completamente dependentes do paternalismo do Estado?

\subsection{Os desafios para a aplicabilidade da Lei no 9.474/97 no Brasil}

A realização dos direitos humanos está relacionada com regimes de governo - não é intuito deste artigo analisar essa questão, mas é necessário reiterar que - de acordo com Amartya Sen (2000) - a democracia é locus onde as liberdades e o desenvolvimento melhor se manifestam. Isto porque os países que têm mais acesso às liberdades, em que as pessoas podem escolher e cobrar posicionamentos dos seus governantes, são menos desiguais.

Ditaduras militares, como a que ocorreu no Brasil, são exemplo de governos que limitam a liberdade individual e coletiva, além de privá-los arbitrariamente de direitos. O solo da democracia é espaço fértil para a efetivação de direitos não apenas de nacionais, como também de estrangeiros. O preâmbulo do Texto Magno de 1988 afirma que a sociedade está "fundada na harmonia social e comprometida, na ordem interna e internacional, com a solução pacífica das controvérsias".

O Brasil é reconhecido internacionalmente como país diplomático e que busca soluções pacíficas. Suas iniciativas em relação à temática de refugiados tornam-no referencial para outros países, segundo o Alto Comissariado das Nações Unidas (ACNUR, 2018), pois o Estado brasileiro não apenas assinou a Convenção dos 
Refugiados de 1951, como também criou o Comitê Nacional para os Refugiados (Conare) por meio da Lei no 9.474 de 22 de julho de 1997. A projeção que essa lei demonstra é que refugiados - ou seja, aqueles que não escolheram sair do seu país a turismo, mas foram obrigados, caso contrário poderiam morrer - também precisam ter oportunidades sociais adequadas.

\subsection{0 caso dos refugiados da Venezuela no Brasil}

A crise política, econômica e social na Venezuela - consequência de um governo ditatorial desrespeitador dos direitos humanos e da democracia - tornou-se notícia no mundo inteiro quando centenas de venezuelanas iniciaram um êxodo em busca de refúgio em países vizinhos na América Latina. Entre os países que mais os receberam está o Brasil, por ser fronteira entre a cidade de Pacaraima (Roraima-Brasil) e Santa Elena de Uairén (Venezuela).

Em 2018, a chegada massiva de refugiados venezuelanos em Roraima teve como consequência crises relacionadas à segurança pública, xenofobia e superlotação em postos de saúde, razão pela qual o Governo do Estado, por meio do Decreto Estadual no 25.681, de 10 de agosto de 2018, determinou que as forças de segurança pública garantissem a segurança local e inibissem a entrada de mais refugiados na fronteira. Insta-se salientar que os efeitos do referido decreto foram suspensos pela Ministra Rosa Weber, do Supremo Tribunal Federal.

$\mathrm{Na}$ ação junto ao STF, o Estado de Roraima teve insucesso no seu pedido de fechamento da fronteira ou contingenciamento na entrada dos venezuelanos, ao justo fundamento judicial de que a Lei no 13.684/2018 garante medidas de assistência emergencial para acolhimento de pessoas em situação de vulnerabilidade advindas de outros países por crise humanitária, com o objetivo maior de garantir o respeito à dignidade humana.

Os princípios de universalidade dos direitos humanos e de combate a toda forma de discriminação ao migrante, e ainda o combate à xenofobia, são princípios fundamentais nas decisões judiciais em casos de crise humanitária.

Com Amartya Sen (2000) foi visto a importância das oportunidades sociais aos indivíduos, de sorte que o ciclo de oportunidades faz com que aqueles que têm acesso à direitos sociais credenciam a outros os mesmos direitos. Confrontando esta doutrina ao caso de Roraima, a sobrecarga do Estado para lidar com as dificuldades já vividas pelos brasileiros lá residentes ficou mais gravosa com a chegada dos venezuelanos, e, assim, as poucas oportunidades sociais se tornaram-se mais escassas. Por isso, a realidade local ocasionou exatamente o contrário do que prega Sen (2000) sobre oportunidades aos cidadãos em uma sociedade desenvolvida.

A reserva do possível, todavia, não deve ser argumento que impeça a realização do direito fundamental neste estudo pregado: mínimo existencial aos refugiados estrangeiros, em particular os venezuelanos. $\mathrm{Na}$ verdade, como bem observa Olsen (2008a), a reserva do possível é um argumento político que trata sobre a escassez de recursos para a efetivação dos direitos sociais. Tal argumento pode ser refutado, visto que existem medidas para que não haja sobrecarga orçamentária, como a divisão equitativa de grupos de refugiados para outros Estados e municípios, além das medidas constitucionais/legais.

Nesse sentido, a ministra Rosa afirma que:

Há, portanto, informações preliminares a demonstrar esforços feitos pela ré em tal sentido. Todavia os números aparentemente são ínfimos, dado o noticiado constante fluxo de entrada de novos migrantes no território roraimense - não obstante parte deles retorne ao país de origem ou se desloque espontaneamente para outros Estados brasileiros. Parece evidente haver um crescente contingente populacional de venezuelanos em Roraima com consequente aumento de despesas nos serviços públicos. A absoluta incerteza sobre a duração deste triste êxodo humano e o impacto diário deste fenômeno no custo dos serviços públicos dos entes federativos mais próximos desta porta de entrada brasileira - no presente caso os municípios fronteiriços e o Estado de Roraima - conduzem à urgente e necessária aceleração do processo de interiorização, como "válvula de descompressão" da questão litigiosa (STF - AÇÃO CÍVEL ORIGINÁRIA, 2018).

Observa-se que ao proferir sua decisão, a ministra Rosa reconhece o esforço da União no acolhimento dos refugiados, no entanto evidencia-se que diante do fluxo de entrada no Brasil, os esforços são ínfimos. Des- 
sa forma, a relatora sugere a aceleração do processo de interiorização dos refugiados, ou seja, sua distribuição equitativa para os Estados brasileiros com vista à redução dos impactos sofridos por Roraima e na devida acoIhida humanitária.

A Lei no 9.474/74 determina que os Ministérios governamentais trabalhem em conjunto para a realização de todas as etapas que regularizam o ingresso do refugiado em território nacional. Após ser reconhecido juridicamente como refugiado, o indivíduo passa a ter os deveres e direitos previstos na Convenção Relativa ao Estatuto dos Refugiados de 1951, conforme os artigos 50 e 6ㅇ da Lei anteriormente citada.

Entre os deveres do refugiado inclui-se a obrigação de respeitar as leis e regulamentos do país que lhe concede refúgio. Seus direitos são semelhantes aos direitos fundamentais do artigo 5o do Texto Magno, não podendo serem privados, sob nenhum argumento ou pretexto, do mínimo para viver.

Tais direitos são o de ter documento de identidade, de viagem e Carteira Profissional de Trabalho (CTPS), o direito a ter alojamento e direito à propriedade, proteção à sua propriedade intelectual, direito de ter acesso a tribunais e à Justiça gratuita, direito à associação, direito a trabalhar com carteira assinada ou como profissional liberal, direito ao reconhecimento de seus diplomas em território nacional, direito à assistência pública, previdência social, assistência administrativa e à educação pública.

O direito fundamental perseguido é o de viver que diz respeito à qualidade de vida. E não de sobreviver! Torres (2003) define como direitos indispensáveis a alimentação, segurança, saúde e educação. Sem alimentação há a desnutrição e até a morte. Sem segurança uma pessoa poderia estar vulnerável a perigos contra sua própria vida. Sem saúde adequada e assistência preventiva, pode-se chegar à morte. Sem educação o indivíduo não goza de outros direitos, não usufrui da plenitude de sua capacidade de aprendizado e não desenvolve nem a si mesmo e nem a sociedade ao seu redor. Desprovidos desses mínimos direitos conjuntamente, à pessoa resta viver sempre no mesmo patamar de sobrevivência.

\section{CONSIDERAÇÕES FINAIS}

A temática de refúgio é problema que ultrapassa as fronteiras nacionais, em que indivíduos têm seus direitos tolhidos e enfrentam constantes ameaças à vida. Desprovidos de seus direitos básicos, buscam refúgio - geralmente - em países vizinhos. Por isso, no caso do Brasil a lei que estabelece as diretrizes de criação do Conare é altamente relevante.

Observou-se ao longo deste artigo que o trabalho de coordenação e organização da acolhida e interiorização dos refugiados venezuelanos é fundamental para não sobrecarregar nenhum município ou Estado. Veja-se que em momento algum é questionado se os venezuelanos podem ou não se refugiar no Brasil, pois este é um direito internacional que eles possuem, de acordo com a adesão brasileira ao Estatuto dos Refugiados de 1951.

Essa perspectiva está de acordo com a sentença proferida pela ministra Rosa Weber, que indeferiu o pedido do governo de Roraima para o fechamento ou contingenciamento da fronteira da Venezuela com o Brasil. Assim sendo, o que se deve realizar é uma melhor e mais ágil organização logística e orçamentária no processo de interiorização dos refugiados.

O argumento da reserva do possível, ou seja, das limitações orçamentárias do país decaem diante das necessidades básicas dos refugiados. E mais, a interiorização equitativa dos refugiados de acordo com as possibilidades dos Estados federativos facilita o seu atendimento. Como estabelecido na formação do Conare, os Ministérios da União em conjunto com organizações da sociedade civil e o Alto Comissariado das Nações Unidas para Refugiados (ACNUR), são responsáveis por todo esse processo de acolhimento, servindo como facilitadores.

Pode-se concluir que os princípios de justiça e solidariedade permearam as análises realizadas no presente artigo. De fato, os direitos sociais previstos na Constituição Federal possuem vasta relação com a Lei no 9.474/97, constituindo uma extensão de direitos para os refugiados justamente por entender que a justiça e a solidariedade, bem como os direitos que são inerentes à humanidade, se sobrepõem às reservas orçamentárias.

Os relatórios do Alto Comissariado das Nações Unidas (ACNUR) de 2018 e do Programa das Nações Unidas para o Desenvolvimento (PNUD) de 2017, ao demonstrarem, respectivamente, a situação dos refugiados 
no mundo e no Brasil, e sobre o Estado de Bem-Estar Social no Brasil, com dados sobre a desigualdade social, extrema pobreza e o acesso ineficiente à saúde e à educação, só fazem confirmar o quanto o Brasil ainda precisa desenvolver-se para minimizar, pelo menos, a vulnerabilidade dos refugiados, e promover-lhes situação fática semelhante à situação jurídica prevista no ordenamento legal brasileiro.

Os direitos fundamentais sociais garantidos aos refugiados na Lei $n$ o 9.474/97 e reconhecidos juridicamente pelo Estado brasileiro por meio do Conare devem ser concretamente realizados não apenas para assegurar o mínimo existencial como também o acesso às oportunidades.

O Estado Democrático de Direito promove o respeito aos direitos e liberdades, o que condiciona oportunizar o efetivo acesso aos direitos fundamentais sociais não só do nacional, mas igualmente do refugiado, em razão do cenário jurídico brasileiro construído para ampará-los.

Os princípios da igualdade, da solidariedade e da Justiça ensejam a incondicional concreção do direito ao mínimo existencial dos refugiados, não se admitindo o argumento da reserva do possível para que não haja sua realização, diante da homenagem à dignidade da pessoa humana.

\section{REFERÊNCIAS}

ACNUR. Declaração do Brasil: Um Marco de Cooperação e Solidariedade Regional para Fortalecer a Proteção Internacional das Pessoas Refugiadas, Deslocadas e Apátridas na América Latina e no Caribe. Brasília: ACNUR, 2014, p. 1-19.

ACNUR. Brasil. Protegendo refugiados no Brasil e no mundo. Brasília: Acnur, 2018. Disponível em: https://www.acnur.org/ portugues/wp-content/uploads/2018/02/Protegendo-Refugiados-no-Brasil-e-no-Mundo_ACNUR-2018.pdf. Acesso em: 9 jul. 2019.

ACSP. Impostômetro. Associação Comercial de São Paulo. Disponível em: https://impostometro.com.br/ Acesso em: 13 jul. 2019.

ANDRADE, Varelia Pereira de; RAMINA; Larissa. Refúgio e dignidade da pessoa humana: breves considerações. In: ANNONI, Danielle (org.). Direito Internacional dos Refugiados e o Brasil. Curitiba: Gedai; UFPR, 2018.

BRASIL. Decreto $n^{\circ}$ 9.285, de 15 de fevereiro de 2018. Reconhece a situação de vulnerabilidade decorrente de fluxo migratório provocado por crise humanitária na República Bolivariana da Venezuela. Brasília: Casa Civil, 2018 .

BRASIL. Lei $n^{\circ}$ 9.474, de 22 de julho de 1997. Define mecanismos para a implementação do Estatuto dos Refugiados de 1951, e determina outras providências. Brasília: Executivo, 1997.

BRASIL. Lei $n$ o 13.684, de 21 de junho de 2018. Dispõe sobre medidas de assistência emergencial para acolhimento a pessoas em situação de vulnerabilidade decorrente de fluxo migratório provocado por crise humanitária; e dá outras providências. Brasília: Executivo, 2018b.

BRASIL. Nações Unidas no Brasil. Avanços e desafios da proteção aos refugiados no Brasil. Brasília, dez. 2014.

BRASIL. Constituição da República Federativa do Brasil de 1988. Brasília, DF: Senado Federal; Centro Gráfico, 1988.

EL PAÍS. Informações sobre a crise dos refugiados venezuelanos. El País. Disponível em: https://elpais.com/agr/el_exodo_venezolano/a. Acesso em: 20 jul. 2019.

GONZÁLEZ, Juan Carlos Murillo. A importância da lei brasileira de refúgio e suas contribuições regionais. In: BARRETO, Luiz Paulo Teles (org.). Refúgio no Brasil: a proteção brasileira aos refugiados e seu impacto nas Américas. 1. ed. Brasília: Acnur; Ministério da Justiça, 2010. p. 50-58.

LINKLATER, Andrew. The Transformation of Political Community: Ethical Foundations of the Post-Westphalian Era. Cambridge: Polity Press, 1998.

MATOS, Monique Fernandes Santos. A universalidade dos direitos sociais nas jurisprudências das cortes europeia e interamericana de direitos humanos. 2015. 182 p. Dissertação (Mestrado em Direito das Relações Internacionais) - UniCEUB, Brasília, 2015.

MATTOS NETO, Antonio José (coord.). Estado democrático de direitos e direitos humanos. São Paulo: Saraiva, 2010.

OLSEN, Ana Carolina Lopes. A eficácia dos direitos fundamentais sociais frente à reserva do possível. 2006.378 p. Dissertação (Mestrado) - Universidade Federal do Paraná, UFPR, Pós-Graduação em Direito do Setor de Ciências Jurídicas, Curitiba, 2006.

OLSEN, Ana Carolina Lopes. Direitos fundamentais sociais como regras e princípios. In: Direitos fundamentais sociais: efetividade frente à reserva do possível. Curitiba: Juruá, 2008a. p. 63-113.

OLSEN, Ana Carolina Lopes. O preceito da proporcionalidade como proibição da insuficiência. In: Direitos Fundamentais sociais: efetividade frente à reserva do possível. Curitiba: Juruá, 2008b. p. 247-298. 


\section{Direito自 \\ Debate}

\section{DESENVOLVIMENTO X RESERVA DO POSSÍVEL NO CENÁRIO DO ESTADO DEMOCRÁTICO BRASILEIRO: \\ O CASO DOS REFUGIADOS VENEZUELANOS \\ Antônio José de Mattos Neto - Thaise Roberta Colares Leal}

ORGANIZAÇÃO DAS NAÇÕES UNIDAS. Declaração Universal dos Direitos Humanos. 1948. Disponível em: https://www.unicef. org/brazil/declaracao-universal-dos-direitos-humanos. Acesso em: 3 jan. 2020.

PALMA, Rodrigo. História do Direito Brasileiro na República: do fim do Estado Novo ao processo de redemocratização (19451988). In: História do Direito. 5. ed. São Paulo: Saraiva, 2015.

PEIXOTO, Amanda Endler. Refugiados ambientais e seu deslocamento forçado: uma análise do tratamento legal. 2020. $47 \mathrm{f}$. Monografia - Núcleo de Trabalho de Curso da UniEvangélica, Anapolis, 2020.

PNUD. Programa das Nações Unidas para o Desenvolvimento. Desenvolvimento humano para além das médias. Brasília: PNUD; Ipea; FJP, 2017.

ROCHA, Amanda Bernardes da; GUERRA, Sidney. O direito internacional dos refugiados e a eficácia acerca do sistema brasileiro de concessão de refúgio. Revista Acadêmica de Direito da Unigranderio, v. 9, n. 1, 2019.

RORAIMA, Estado. Decreto $n^{\circ} 25.681-E$, de 01 de agosto de 2018. Decreta atuação especial das forças de segurança pública e demais agentes públicos do Estado de Roraima em decorrência do fluxo migratório de estrangeiros em território do Estado de Roraima e dá outras providências. Roraima: Governo Estadual, 2018.

SARDENBERG, Ronaldo Mota. A experiência brasileira nas Nações Unidas. In: SARDENBERG, Ronaldo Mota. O Brasil e as Nações Unidas. Brasília: Fundação Alexandre de Gusmão - Funag, 2013. p. 85-97.

SEN, Amartya. Desenvolvimento como liberdade. São Paulo: Companhia das Letras, 2000.

STF. Ação Cível Originária. ACO 3121 RR: 0069076-95.2018.1.00.0000. Relatora: Ministra Rosa Weber. DJ: 23/08/2018. JusBrasil, 2018. Disponível em: http://portal.stf.jus.br/processos/detalhe.asp?incidente=5437155. Acesso em: 10 jul. 2019.

TORRES, Ricardo Lobo. A metamorfose dos direitos sociais em mínimo existencial. In: SARLET, Ingo Wolfgang (org.). Direitos fundamentais: estudos de direito constitucional, internacional e comparado. Rio de Janeiro: Renovar, 2003. p. 1-46.

UNDP. Human Development Indices and Indicators. Washington: United Nations Development Programme, 2018.

UNDP. Human Development Report 2019. Beyond income, beyond averages, beyond today: Inequalities in human development in the 21st century. New York: United Nations Development Programme, 2019. 